\title{
Study on Preparation of Y-90 Microspheres in Da Lat Nuclear Reactor for Application in Treatment of Primary and Secondary Liver Cancers
}

\author{
PHAM THANH MINH ${ }^{1 *}$, DUONG VAN DONG ${ }^{1}$, LE VAN THUAN ${ }^{2,3}$, \\ TRUONG MINH TRI ${ }^{4}$, TRUONG DUC TOAN ${ }^{1}$ and CAO DONG VU1 \\ ${ }^{1}$ Nuclear Research Institute, Dalat City, Vietnam. \\ ${ }^{2}$ Center for Advanced Chemistry, Institute of Research \& Development, Duy Tan University, \\ Danang City, Vietnam. \\ ${ }^{3}$ Graduate University of Science and Technology, Vietnam Academy of Science and Technology, \\ Hanoi, VietNam. \\ ${ }^{4}$ The Mientrung Institute for Chemistry and Environment Research, Mien Trung University of Civil \\ Engineering, Tuy Hoa City, Vietnam. \\ ${ }^{*}$ Corresponding author E-mail: phamthanhminhnridl@gmail.com \\ http://dx.doi.org/10.13005/ojc/360414
}

(Received: July 20, 2020; Accepted: August 20, 2020)

\begin{abstract}
In this article, Y-90 microspheres are synthesized in three forms (resin microspheres, glass microspheres and gel microspheres) in Da Lat Nuclear Reactor (Vietnam) with a capacity of $500 \mathrm{~kW}$ for application in treatment of primary and secondary liver cancers. Characterization and quality of Y-90 microspheres are checked by field emission scanning electron microscopy (FE-SEM), energydispersive X-ray spectroscopy (EDX), chemical purity, radionuclide purity, radiochemical purity, sterility, bacterial endotoxins, toxic heavy metals (ICP-MS) and product stability over time. The results showed that Y-90 resin microspheres, Y-90 glass microspheres and Y-90 gel microspheres with particle sizes of 20-30 $\mu \mathrm{m}$ have a high specific activity to meet the quality standards of radiopharmaceuticals according to British Pharmacopoeia 2016. This is a promising radiopharmaceuticals in treatment of primary and secondary liver cancers using radioembolization in Vietnam.
\end{abstract}

Keywords: Radiopharmaceutical, Y-90 resin microspheres, Y-90 glass microspheres, Y-90 gel microspheres, Primary and secondary liver cancers.

\section{INTRODUCTION}

Hepatocellular carcinoma (HCC) is one of the most common malignant diseases and is becoming more and more globally at increasingly young ages ${ }^{1}$.
Around the world, liver cancer is now common in many countries. More than 800,000 people are diagnosed with this cancer each year. Liver cancer is also the leading cause of cancer deaths worldwide, accounting for over 700,000 deaths every year ${ }^{1}$.

This is an Open Access article licensed under a Creative Commons license: Attribution 4.0 International (CC- BY). Published by Oriental Scientific Publishing Company @ 2018 
In Vietnam, liver cancer is rated as the most common disease nowadays. It usually originates from cirrhosis due to hepatitis $B$ virus, hepatitis $C$ virus, alcoholism, etc. Liver cancer is the $3^{\text {rd }}$ leading cause of death after lung cancer and stomach cancer. Its prognosis is extremely bad, and the average survival time of the patient is only ${ }^{3-6}$ months of detection ${ }^{2}$.

Radioembolization or Selective internal radiation therapy (SIRT) using radioactive drug (Ytrium-90)-attached microspheres administered directly into the liver tumor through the artery is a modern intervention treatment and being applied increasingly popular in recent years. This is a selective form of radiation to concentrate a high dose of radiation in the tumor and minimize damage to surrounding healthy liver. An advantage of radioembolization is that it can destroy metastatic thrombosis, it is therefore indicated for hepatocellular cancers with portal vein invasion (branches, subbranches) $)^{3,4}$.

$\mathrm{Y}-90$ is a radioactive isotope applied extensively in nuclear medicine for cancer treatment as it emits pure beta having a maximum energy of 2.27 MeV with a half-life of 2.6 days and penetrating hepatic tissues at an average of $2.5 \mathrm{~mm}^{5}$. Y-90 is produced by two methods: Y-90 separation from ${ }^{90} \mathrm{Sr} /{ }^{90} \mathrm{Y}$ isotope generator in which $\mathrm{Sr}-90$ is a product of fission of $\mathrm{U}-235$ and irradiation of ${ }^{89} \mathrm{Y}_{2} \mathrm{O}_{3}$ enriched in the nuclear reactor ${ }^{6}$.

The two companies currently engaged in production and distribution of $\mathrm{Y}-90$ microspheres are: TheraSphere $\circledast$, manufactured by BTG International (London) and approved by the U.S. Food and Drug Administration (FDA) in 1999 for treatment of incurable hepatocellular carcinoma, and SIRSpheres $\AA$ of Sirtex Medical (Sydney), approved by the FDA in $2002^{7}$. Now, SIR-Spheres is being used in Australia and Europe to treat liver cancer patients. In the United States, SIR-Spheres in combination with adjuvant hepatic arterial chemotherapy using fluorouridine is indicated for treatment of undetectable metastatic liver tumors from primary colorectal cancer ${ }^{8}$.

SIR-Spheres are biocompatible radioactive resin microspheres attached $90 \mathrm{Y}$ on a polystyrene cation-exchange resin layer through the ion exchange of $\mathrm{Na}^{+}$with ${ }^{90} \mathrm{Y}^{3+} .{ }^{90} \mathrm{Y}$ is then fixed to the resin microspheres by precipitating them in the form of phosphate salts ${ }^{8}$. Despite being fixed, ${ }^{90} Y$ is still dissociated in ionic solutions (water, salt water). According to the article, $0.01 \%-0.4 \%$ of ${ }^{90} \mathrm{Y}$ microspheres will dissociate in water after 20 minutes. The rest will be permanently bound to microspheres and not dissociated under physiological conditions.

Thera Sphere are biocompatible radioactive glass microspheres which are manufactured by mixing ${ }^{89} \mathrm{Y}_{2} \mathrm{O}_{3}$ with super-pure $\mathrm{Al}_{2} \mathrm{O}_{3}$ and $\mathrm{SiO}_{2}$ and then melted in a furnace at $1500^{\circ} \mathrm{C}$. After cooling, glass ${ }^{89} \mathrm{Y}$ is ground and rounded to the surface by spraying through a high-rise heating system using gas or oxygen heat treatment. Glass microspheres are sieved to select those with diameters of 20-30 $\mu \mathrm{m}$. These glass microspheres are then irradiated in a nuclear reactor to generate ${ }^{90} \mathrm{Y}$ from ${ }^{89} \mathrm{Y}_{10}$.

Currently, many authors have conducted researches on synthesizing Y-90 gel microspheres in different nuclear reactors. These results show that Y-90 gel microspheres can be effectively applied in liver cancer treatment in medicine $e^{8,9,10}$.

In Vietnam, there is no research on preparation of radioactive drug as $\mathrm{Y}-90$ microspheres. In order to keep up with the development of modern medicine in the world, the ability to localize and the need of liver cancer treatment in Vietnam, we have conducted a research on preparation of Y-90 Microspheres in the forms of resin microspheres, glass microspheres and gel microspheres in $\mathrm{Da}$ Lat nuclear reactor with a low capacity of $500 \mathrm{~kW}$ for the purpose of manufacturing and application in liver cancer treatment, contributing to active and effective community health care.

\section{MATERIALS AND METHODS}

\section{Materials}

Cation-exchange resin (Biotechnology Grade Bio-Rex70 Resin with diameters of 20-30 $\mu \mathrm{m})$ manufactured by Bio-rad Company, USA. All the chemicals used in this study including $\left.\mathrm{Y}_{2} \mathrm{O}_{3} 99.9 \%, \mathrm{SiO}_{2} 99.9 \%, \mathrm{Al}_{2} \mathrm{O}_{3} 99.9 \%, \mathrm{Y}_{\left(\mathrm{NO}_{3}\right.}\right)_{3}$ $99.9 \%$, Ascorbic acid, $\mathrm{Na}_{3} \mathrm{PO}_{4} 96 \%, \mathrm{NH}_{4} \mathrm{OH}$ $25 \%, \mathrm{HNO}_{3} 68 \%$, 2-ethylhexanol $99.7 \%$, Span 80 $99.8 \%$, Octadecylamine $99.8 \%, \mathrm{C}_{2} \mathrm{H}_{5} \mathrm{OH} 99.5 \%$, $\mathrm{CH}_{3} \mathrm{COONH}_{4} 99 \%, \mathrm{Na}_{2} \mathrm{HPO}_{4} .7 \mathrm{H}_{2} \mathrm{O} 99.6 \%, \mathrm{HCl}$ $36.5 \%, \mathrm{NaOH} 98 \%$ were purchased from Merck (Germany). All the other chemicals were used without further purification. 


\section{Preparation of $\mathrm{Y}-90$ resin microspheres}

Irradiate $1 \mathrm{~g}$ of ${ }^{89} \mathrm{Y}_{2} \mathrm{O}_{3}$ in Da Lat nuclear reactor with the following parameters: Reactor capacity $(500 \mathrm{~kW})$; Thermal neutron flux $\left(2.3 \times 10^{13} \mathrm{n} / \mathrm{cm}^{2} / \mathrm{s}\right)$; Irradiation duration (180 hours); Cooling duration (24 hours). After irradiation, dissolve ${ }^{90} \mathrm{Y}_{2} \mathrm{O}_{3}$ in $10 \mathrm{~mL}$ of concentrated $\mathrm{HCl} 36.5 \%$, add $5 \mathrm{~mL}$ of $\mathrm{H}_{2} \mathrm{O}_{2} 30 \%$ in a 3-neck flask with a reflux condenser and then heat on a magnetic stirrer for 2 hours. After the solution is completely dissolved, evaporate it and dissolve it with $5 \mathrm{~mL}$ of $\mathrm{HCl} 1 \mathrm{M}$, obtain ${ }^{90} \mathrm{YCl}_{3}$ solution ${ }^{6}$.

Resin equilibration: Immerse $2 \mathrm{~g}$ of Bio-Rex70 Resin in $100 \mathrm{~mL}$ of ammonium acetate $0.1 \mathrm{M}$ for 30 min then adjust $\mathrm{pH}$ 5.5-6.0 until the $\mathrm{pH}$ becomes stable and allow it to equilibrate for 30 minutes. Next, pour the solution and repeat the above steps until a new solution is added and the $\mathrm{pH}$ value is constant ${ }^{11}$.

Put $5 \mathrm{mg}$ of Bio-Rex70 Resin into a vial containing $1 \mathrm{~mL}$ of ammonium acetate $0.1 \mathrm{M}$ ( $\mathrm{pH}$ 5.5-6.0). Then, add $5 \mathrm{mCi}$ of ${ }^{90} \mathrm{YCl}_{3}$ solution. The reaction is carried out in a vortex system at a speed of 25-200 rpm for 5-60 min $\mathrm{pH} 3-8$, and at a temperature of $22-60^{\circ} \mathrm{C}$. At the end of reaction, separate resin microspheres marked Y-90 by centrifugation at $1200 \mathrm{rpm}$, then wash them with sodium phosphate buffer $0.2 \mathrm{M}(\mathrm{pH} 7.4)$ until $\mathrm{pH}$ of the washing solution is less than 8.5. The final product is contained in $2 \mathrm{~mL}$ of sodium phosphate buffer $0.2 \mathrm{M}(\mathrm{pH} 7.4)$ for further studies ${ }^{12}$.

\section{Preparation of Y-90 glass microspheres}

Y-90 glass microspheres were synthesized with the following components ${ }^{10}$.

Table 1: Survey of components forming Y-90 glass microspheres

\begin{tabular}{lccc}
\hline Sample & $\mathrm{SiO}_{2}(\% . w)$ & $\mathrm{Al}_{2} \mathrm{O}_{3}(\% . w)$ & $\mathrm{Y}_{2} \mathrm{O}_{3}(\% . w)$ \\
\hline GL1 & 20 & 10 & 70 \\
GL2 & 70 & 10 & 20 \\
GL3 & 70 & 20 & 10 \\
GL4 & 20 & 45 & 35 \\
\hline
\end{tabular}

Exactly weigh according to the predetermined weights (Table 1 ) into a platinum crucible and place it in an electric furnace at $1600^{\circ} \mathrm{C}$ for 2 hours. Quickly move the product out, mix well and pour quickly into the cold water to create a breaking effect. Sort products into groups of different sizes suitable for the purpose of use. Glass particles now need to be rounded and smoothed the surface by spraying through a high-rise heating system using gas or oxygen heat treatment. At the end of this process, sort particles again to select the right product for use ${ }^{10}$. This product contains an amount of $\mathrm{Y}-89$ in the components and was gone through a neutron irradiation in $\mathrm{Da}$ Lat nuclear reactor with the following irradiation parameters: Thermal neutron flux $\left(2.3 \times 10^{13} \mathrm{n} / \mathrm{cm}^{2} / \mathrm{s}\right)$; Sample weight $(1 \mathrm{~g})$; Irradiation duration (180 h); Cooling duration (24 h). After irradiation, Y-90 glass microspheres were obtained and dissolved in $5 \mathrm{~mL}$ of $\mathrm{NaCl} 0.9 \%$ for further studies.

\section{Preparation of Y-90 gel microspheres}

Sol formation: Prepare $\mathrm{Y}\left(\mathrm{NO}_{3}\right)_{3}$ by dissolving $2 \mathrm{~g}$ of $\mathrm{Y}_{2} \mathrm{O}_{3}$ powder in concentrated $\mathrm{HNO}_{3}$ solution with a mass ratio of $1: 3$ on a reflux heating system. After cooling, dilute the solution with $100 \mathrm{~mL}$ of distilled water twice and slowly add concentrated $\mathrm{NH}_{4} \mathrm{OH}$ solution until a precipitate of $\mathrm{Y}(\mathrm{OH})_{3}$ appears. Filter precipitate and wash it with distilled water twice until the filtrate reaches $\mathrm{pH}$ 7. Then, put the precipitate into a beaker and dissolve it with distilled water twice, stir until the solution formed a paste. Add $2 \mathrm{~g}$ of ascorbic acid to above mixture, stir for $30 \mathrm{~min}$ at $50^{\circ} \mathrm{C}$ to form a bright yellow complex (Y-ascorbic-H2O-NH+4 $)^{13}$.

Gel formation: Put $100 \mathrm{~mL}$ of 2-ethylhexanol-1 solution into a beaker containing the complex (Y-ascorbic- $\mathrm{H}_{2} \mathrm{O}-\mathrm{NH}+{ }^{4}$ ), add $2 \%$ of Span-80 solution and $2 \mathrm{~mL}$ of Octadecylamine solution (Octadecylamine soluble in petroleum at a ratio of $1: 1)$, stir for $30 \mathrm{~min}$ at room temperature to form a gel precipitate. Then, wash the gel precipitate three times with $\mathrm{C}_{2} \mathrm{H}_{5} \mathrm{OH}$ solution ${ }^{13}$.

Let the precipitate dry at room temperature for $48 \mathrm{~h}$ then have it dried at $200^{\circ} \mathrm{C}$ for $4 \mathrm{~h}$ at a speed of $1^{\circ} \mathrm{C} / \mathrm{min}$, next heat it at $400^{\circ} \mathrm{C}$ for $2 \mathrm{~h}$ and heat at $650^{\circ} \mathrm{C}$ for $2 \mathrm{~h}$ at a speed of $2^{\circ} \mathrm{C} /$ minute. Finally, put the final product through a sieve with diameter of $63 \mu \mathrm{m}^{13}$. At the end of this process, sort particles again to select the right product for use. This product 
contains an amount of Y-89 in the components and is gone through a neutron irradiation in Da Lat nuclear reactor to obtain Y-90 microspheres. Irradiation conditions: Thermal neutron flux $\left(2.3 \times 10^{13} \mathrm{n} / \mathrm{cm}^{2} / \mathrm{s}\right)$; Sample weight $(1 \mathrm{~g})$; Irradiation duration (180 h); Cooling duration (24 hours).

\section{Characterization and quality test of Y-90 microspheres}

Morphology and size of Y-90 microspheres were tested by field emission scanning electron microscopy FE-SEM (S-4800, Hitachi, $U=10 \mathrm{kV}$ ) at Ho Chi Minh City University of Science, Vietnam ${ }^{14}$. Analysis, testing and evaluation of chemical purity and metal impurity components were done by energy-dispersive $\mathrm{X}$-ray spectroscopy $(\mathrm{EDX})^{15}$. Testing and evaluation of radionuclide purity were carried out by gamma ray spectrometer CanberraGC-3019-7500SL (USA) ${ }^{16}$. Testing and evaluation of radiochemical purity were used the instant thin layer chromatography ITLC in $\mathrm{NaCl} 0.9 \%$ solvent on a Cyclone storage phosphor system ${ }^{17}$. Sterility was tested according to the pharmacopoeia: The drug sample was implanted by direct drug implantation into Fluid thioglycollate medium and Soya-bean casein digest medium. It was implanted into the mediums at a ratio of $4 \mathrm{~mL}$ of sample solution to $40 \mathrm{~mL}$ of medium. Incubate the Fluid thioglycollate medium at $30-35^{\circ} \mathrm{C}$ and Soya-bean casein digest medium at $20-25^{\circ} \mathrm{C}$. Observe for 14 continuous days and read the results everyday ${ }^{18}$. Bacterial endotoxins were tested on Endosafe-PTS 100 (Portable Test System, PTS) according to the pharmacopoeia: Dilute Y-90 microspheres 40 times using distilled water for injection taken from the original bottle of $185 \mathrm{MBq} / \mathrm{mL}$. Take $100 \mu \mathrm{L}$ from the original bottle and dilute into $4 \mathrm{~mL}$, then measure the endotoxins ${ }^{19}$. The testing and evaluation of toxic heavy metals were done with a Inductively-Coupled Plasma - Mass Spectrometry (ICP-MS) ${ }^{20}$. Testing and evaluation of drug stability was conducted through tests such as sensory perception, $\mathrm{pH}$, radiochemical purity and bacterial endotoxins after synthesis of $2 \mathrm{~h}, 4 \mathrm{~h}, 6 \mathrm{~h}$, and 8 hours $^{21}$.

\section{RESULTS AND DISCUSSION}

\section{Effects of factors to synthesis of $\mathrm{Y}-90$ resin microspheres \\ Time}

It was shown from the investigation results that, within 5-10 min yield of Y-90 with Biorex70 resin was quite low (<65\%). Yet, after 15 min yield reached over $70 \%$ and stayed stable up to 60 minutes. As a result, the 15 min duration is selected as an optimal duration for further studies (Figure $1 \mathrm{a}$ ).

\section{pH}

It was shown from the investigation results that, at $\mathrm{pH}$ values of 3-4 and 7-8, the yield of $\mathrm{Y}-90$ with Bio-rex70 resin was less than $70 \%$. This could be explained that Bio-rex70 resin is a weakly acidic cation exchange resin, resulting in cation exchange ability in strong acid medium $(\mathrm{pH} \leq 4)$ and weak alkaline medium $(\mathrm{pH} \geq 7)$. At $\mathrm{pH} 5-6$, the yield is highest (over 70\%) (Figure $1 \mathrm{~b}$ ).

\section{Temperature}

It was shown from the investigation results that, when the temperature was increased to higher than $30^{\circ} \mathrm{C}$, the yield of $\mathrm{Y}-90$ with Bio-rex70 resin gradually decreased. This could be explained that, under an increase in temperature, the bonds between $\mathrm{Y}-90$ and the resin were broken, making the yield less. That is the reason why $22^{\circ} \mathrm{C}$ (room temperature) is selected as the optimal temperature for further studies (Figure $1 \mathrm{c}$ ).

\section{Stirring speed}

It was shown from the investigation results that, the stirring speed of $25-200 \mathrm{rpm}$ did not significantly affect the yield of marking Y-90 with Bio-rex70 resin. Consequently, a stirring speed of about $50 \mathrm{rpm}$ is selected as the optimal speed for the studies (Figure $1 \mathrm{~d}$ ).

\section{Effects of components forming Y-90 glass microspheres}

It was shown from the investigation results that specific activity of $\mathrm{Y}-90$ glass microspheres depends on the initial content of ${ }^{89} \mathrm{Y}_{2} \mathrm{O}_{3}$, in which the samples GL2-GL4 had relatively low radioactivity, the sample GL1 had the highest content of ${ }^{89} \mathrm{Y}_{2} \mathrm{O}$ (70\%.w) and therefore hasd a high radioactivity of $630 \mathrm{mCi} / \mathrm{g}$, which is sufficient for subsequent preclinical studies (Table 2). 

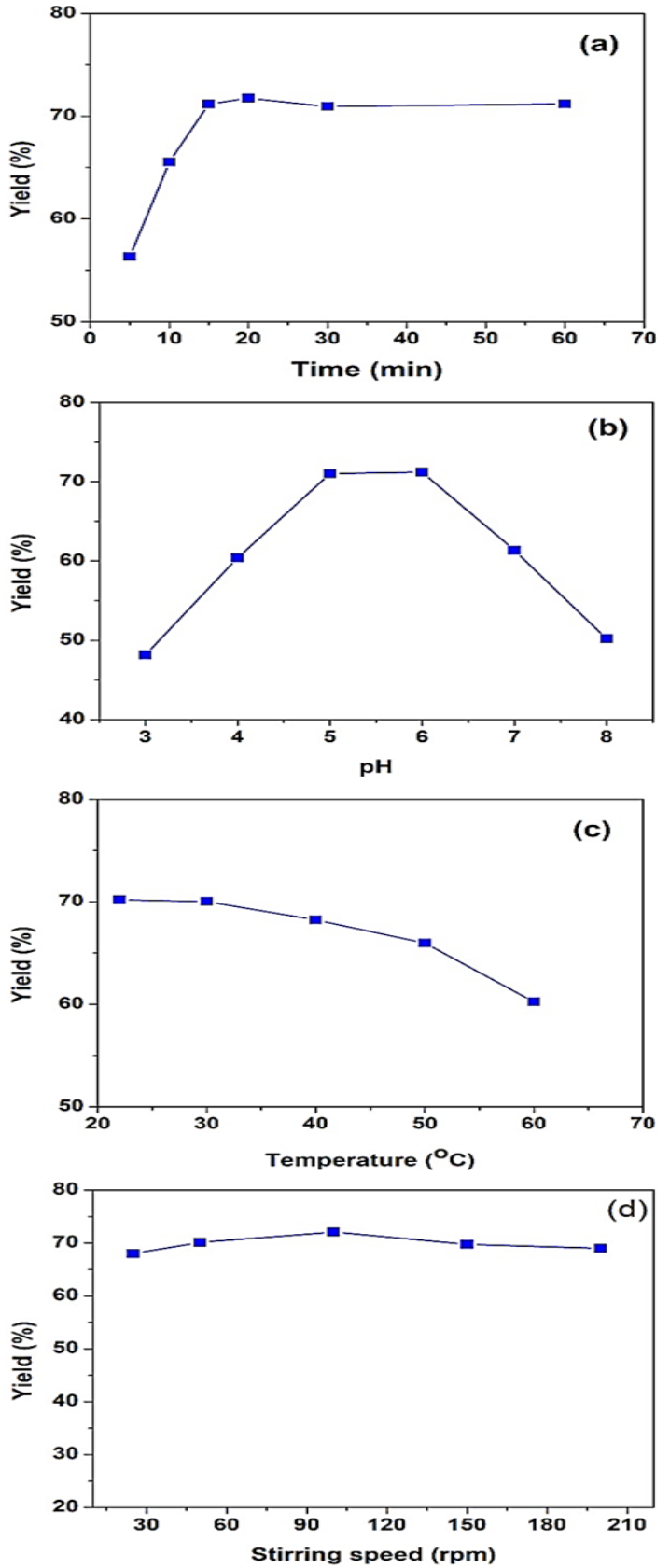

Fig. 1. The effects of time (a), pH (b), temperature (c), and stirring speed (d) to synthesis of Y-90 resin microspheres

Table 2. Result of components forming Y-90 glass microspheres

\begin{tabular}{lcccc}
\hline Sample & $\mathrm{SiO}_{2}(\% . \mathrm{w})$ & $\mathrm{Al}_{2} \mathrm{O}_{3}(\% . \mathrm{w})$ & $\mathrm{Y}_{2} \mathrm{O}_{3}(\% . \mathrm{w})$ & $\begin{array}{r}\text { Relatively } \\
\text { radioactivity } \\
(\mathrm{mCi} / \mathrm{g})\end{array}$ \\
\hline $\mathrm{GL} 1$ & 20 & 10 & 70 & 630 \\
$\mathrm{GL} 2$ & 70 & 10 & 20 & 185 \\
$\mathrm{GL} 3$ & 70 & 20 & 10 & 92 \\
$\mathrm{GL} 4$ & 20 & 45 & 35 & 314 \\
\hline
\end{tabular}

Resulting the preparation of Y-90 gel microspheres

According to the research results, specific activity of $\mathrm{Y}-90 \mathrm{gel}$ microspheres was $950 \mathrm{mCi} / \mathrm{g}$. It was shown from the comparison with $\mathrm{Y}-90$ glass microspheres that, under the same sample irradiation conditions, Y-90 gel microsphere sample had a specific activity 1.3 times higher than the glass microsphere sample. This can be explained that $1 \mathrm{~g}$ of gel microsphere sample contains $100 \%{ }^{89} \mathrm{Y}_{2} \mathrm{O}_{3}$, while the glass microsphere sample contains $70 \%$ ${ }^{89} \mathrm{Y}_{2} \mathrm{O}_{3}$ in $1 \mathrm{gram}$.

\section{Characterization and quality test of Y-90 microspheres}

The surface morphological features of Y-90 resin microspheres, $\mathrm{Y}$-90 glass microspheres and $\mathrm{Y}-90 \mathrm{gel}$ microspheres characterized by FESEM are shown in Fig. 2. It showed that $Y-90$ resin microspheres, Y-90 glass microspheres and Y-90 gel microspheres are spherical and quite uniform with an average size of $20-30 \mu \mathrm{m}$.
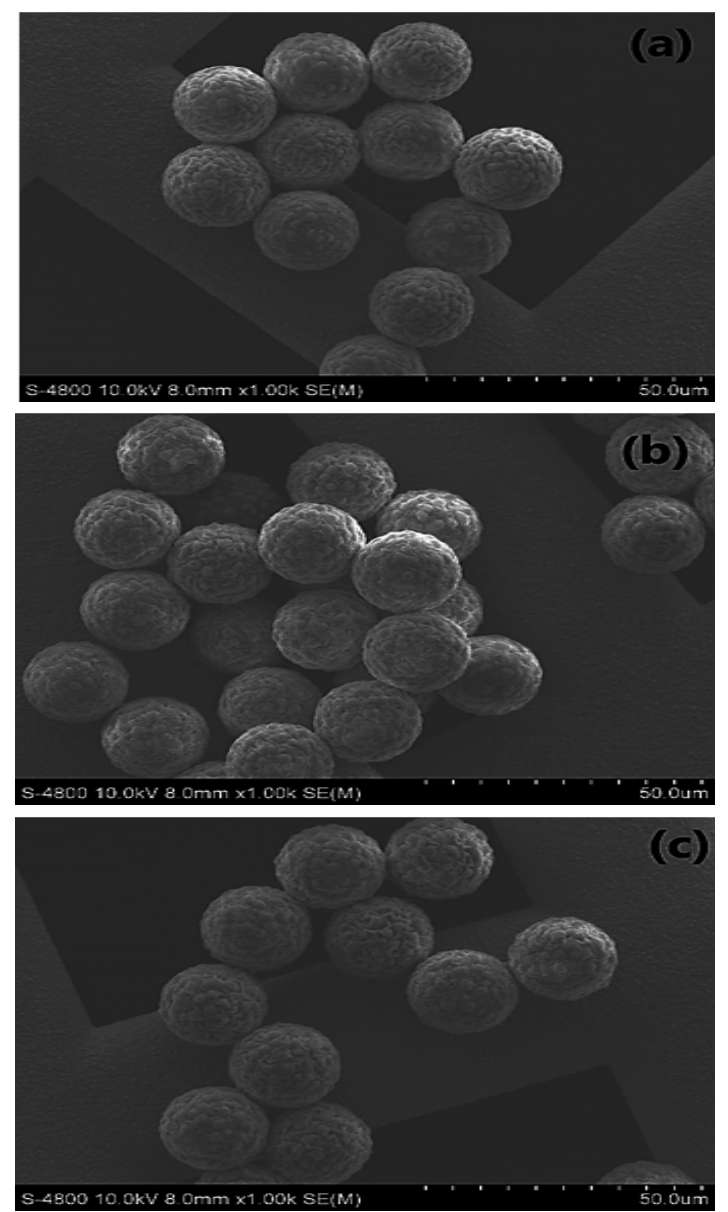

Fig. 2. FE-SEM images of $Y-90$ resin microspheres (a), $Y-90$ glass microspheres (GL1 b) and Y-90 gel microspheres (c) 
The results of analyzing chemical purity and metal impurity components with energydispersive X-ray spectroscopy (EDX) for Y-90 resin microspheres showed that: In addition to elements of resin particles (C (35.43\%.w), O (35\%.w), Na (5.77\%.w), P (3.06\%.w) and S (11.47\%.w)), the Y-90 resin microspheres contained $Y(9.27 \% . w)$. As such, Y-90 microspheres were attached to resin particles with a high chemical purity and in absence of other impurities.

The results of analyzing with energydispersive X-ray spectroscopy (EDX) for Y-90 glass microspheres with sample GL1 showed that the sample GL1 contained 4 main elements including $\mathrm{O}$, $\mathrm{Al}, \mathrm{Si}$ and $\mathrm{Y}$ with their respective component weights and atoms.

The results of analyzing Y-90 gel microspheres with energy-dispersive $\mathrm{X}$-ray spectroscopy (EDX) showed that: the sample contained $Y(68.81 \% . w), O$ (29.91\%).w), and $R b$ (1.28\%.w). Thus, a synthesized Y-90 gel microsphere contained $\mathrm{Y}, \mathrm{O}$, and $\mathrm{Rb}$ as impurity, as $\mathrm{Rb}$ was the element present in the composition of $\mathrm{Y}_{2} \mathrm{O}_{3}$ initially involved in the reaction (accounting for a small amount of $1.28 \%$.w).

The results of testing the radionuclide purity on gamma ray spectrometer (Fig. 3a, 3b, 3c) showed that the $Y-90$ microsphere samples, the radionuclide purity reached $99.5 \%$, the spectrum contained no other gamma-emitting nuclear, there were only I-131 isotopes in the samples (this can be explained that as the testing samples were destroyed one day after production of I-131 isotopes and affected by some I-131 isotopes that had not yet decayed).

The results of testing the radiochemical purity using $1 \times 10 \mathrm{~cm}$ instant thin layer chromatography (ITLC) in $\mathrm{NaCl} 0.9 \%$ solvent on a Cyclone storage phosphor system showed that radioactive impurity of $\mathrm{Y}-90$ microspheres was less than $2.1 \%$ (corresponding to free $Y-90\left(R_{f}=0.9\right)$ and $\mathrm{Y}-90$ microspheres $\left(R_{f}=0.1\right)$ had a purity of higher $97.9 \%$.
Sterility was tested according to the pharmacopoeia: The drug sample was implanted by direct drug implantation into Fluid thioglycollate medium and Soya-bean casein digest medium. It was implanted into the mediums at a ratio of $4 \mathrm{~mL}$ of sample solution to $40 \mathrm{~mL}$ of medium. Incubate the Fluid thioglycollate medium at $30-35^{\circ} \mathrm{C}$ and Soya-bean casein digest medium at $20-25^{\circ} \mathrm{C}$. Observe for 14 continuous days and read the results everyday. The results of testing the sterility on Y-90 microspheres using positive control bottles by visual observation showed that the solution in the bottles was cloudy, which was most evident from the third day, and on the last days, anaerobic and aerobic bacteria thrived in Fluid thioglycollate medium and Soya-bean casein digest medium. Negative control bottles were not infected during the observation. The drug sample bottles observed were also not infected during the observation. Therefore, the samples satisfied the test of sterility.
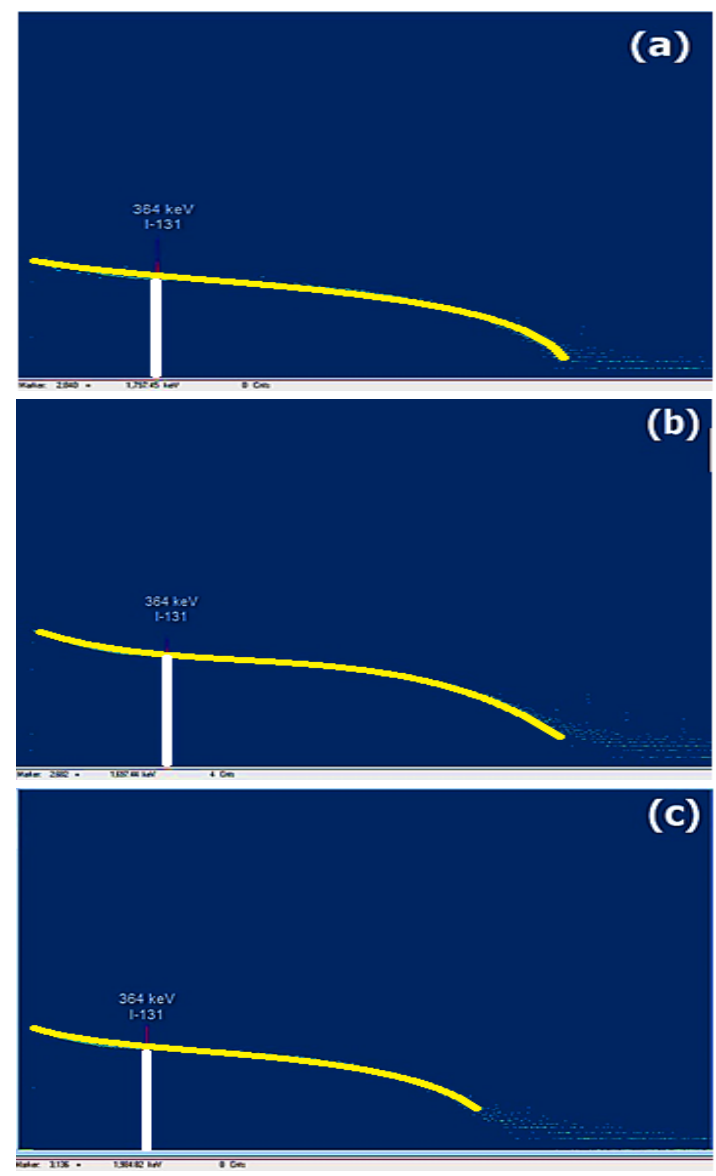

Fig. 3. Radionuclide purity of Y-90 resin microspheres (a), Y-90 glass microspheres (GL1 b) and Y-90 gel microspheres (c) 

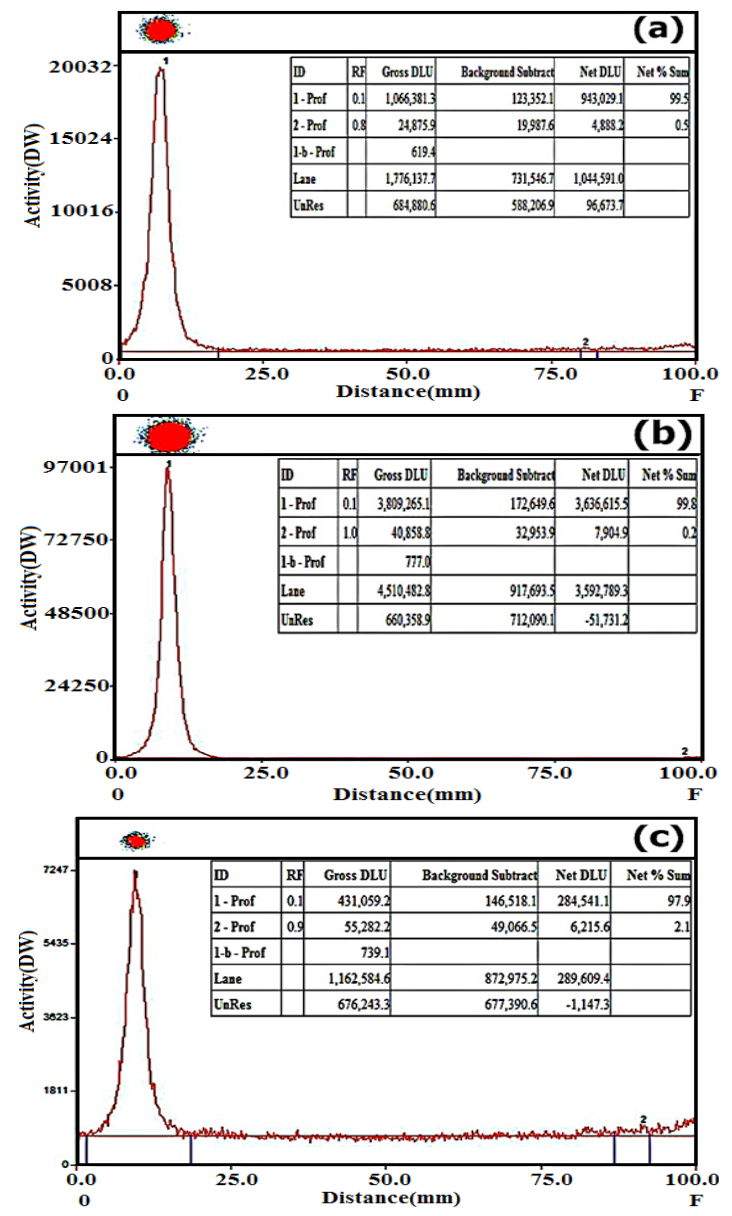

Fig. 4. Radiochemical purity of $\mathrm{Y}-90$ resin microspheres (a), Y-90 glass microspheres (GL1 b) and Y-90 gel
The results of testing the bacterial endotoxins showed that: Content of endotoxins contained in bottles of $\mathrm{Y}-90$ microspheres was measured at $4.35-5.18 \mathrm{EU} / \mathrm{mL}$, this is a single dose per injection. It is assumed that the average human weight is $50 \mathrm{~kg}$, then the endotoxins in the injection dose will be $0.087-0.1104 \mathrm{EU} / \mathrm{mL} / \mathrm{kg}$, respectively. This injection dose is lower than the one specified in the pharmacopoeia (content of endotoxins is less than $5 \mathrm{EU} / \mathrm{mL} / \mathrm{kg}$ ). Therefore, the drug satisfied the test of bacterial endotoxins.

The results of testing the toxic heavy metals using ICP-MS method (Table 3) showed that the contents $\mathrm{Cd}, \mathrm{Hg}, \mathrm{Pb}$, and As were within the allowable ranges specified in the British Pharmacopoeia $2016^{22}$.

The results of testing the drug stability over time immediately after synthesis of $2 \mathrm{~h}, 4 \mathrm{~h}$, $6 \mathrm{~h}$, and $8 \mathrm{~h}$ showed that the items after retesting such as $\mathrm{pH}$ (7.4), radiochemical purity (higher $96 \%$ ), nuclear purity (higher $99 \%$ ) and bacterial endotoxins (less $5 \mathrm{EU} / \mathrm{ml} / \mathrm{kg}$ ) all met the requirements of the pharmacopoeia. Therefore, the drug is stable for 8 hours.

Compare with commercial radiopharmaceuticals Y-90 microspheres (SIR-Spheres $\mathbb{R}$ and TheraSphere ${ }^{\circledR}$. Our radiopharmaceuticals $Y-90$ microspheres synthesized from Dalat nuclear reactor achieved according to British Pharmacopoeia 2016 standards (Table 4).

Table 3: The contents of the toxic heavy metals in Y-90 microspheres

\begin{tabular}{ccccc}
\hline Sample & $\mathrm{Cd}(\mathrm{mg} / \mathrm{kg})$ & $\mathrm{Hg}(\mathrm{mg} / \mathrm{kg})$ & $\mathrm{Pb}(\mathrm{mg} / \mathrm{kg})$ & $\mathrm{As}(\mathrm{mg} / \mathrm{kg})$ \\
\hline Y-90 resin microspheres & $0.015 \pm 0.35$ & $0.010 \pm 0.47$ & $0.48 \pm 0.15$ & $1.32 \pm 0.05$ \\
Y-90 glass microspheres (GL1) & $0.009 \pm 0.19$ & $0.014 \pm 0.33$ & $0.45 \pm 0.19$ & $1.45 \pm 0.23$ \\
Y-90 gel microspheres & $0.008 \pm 0.24$ & $0.011 \pm 0.14$ & $0.43 \pm 1.04$ & $1.47 \pm 0.46$ \\
\hline
\end{tabular}

Table 4: Compare our study with commercial radiopharmaceuticals Y-90 microspheres

\begin{tabular}{cccc}
\hline No. & Quality criteria & British Pharmacopoeia 2016 22 & In this study \\
\hline 1 & $\mathrm{pH}$ & 7,4 & 7,4 \\
2 & Radionuclide purity & $\geq 99,9 \%$ & $99,9 \%$ \\
3 & Radiochemical purity & $\geq 96 \%$ & $\geq 96 \%$ \\
4 & Bacterial endotoxins & $<5 \mathrm{EU} / \mathrm{mL} / \mathrm{kg}$ & $0.087-0.1104 \mathrm{EU} / \mathrm{ml} / \mathrm{kg}$ \\
5 & Sterility & Yes & Yes \\
\hline
\end{tabular}

\section{CONCLUSION}

Y-90 resin microspheres, $\mathrm{Y}-90$ glass microspheres and Y-90 gel microsphere successfully synthesized in $\mathrm{Da}$ Lat nuclear reactor, Vietnam with a capacity of $500 \mathrm{~kW}$ with particle sizes of 
20-30 $\mu \mathrm{m}$ meet the quality criteria for a radioactive drug according to the pharmacopoeia. Y-90 microspheres have a high specific activity (about $950 \mathrm{mCi} / \mathrm{g}$ ) and are capable for preclinical and clinical applications. This is a promising radioactive drug product in treatment of primary and secondary liver cancers using radioembolization in Vietnam.

\section{ACKNOWLEDGMENT}

This work was supported by Graduate University of Science and Technology under grant number GUST.STS.ĐT2017-KHVL02.

\section{Conflict of interests}

No conflict of interest.

\section{REFERENCES}

1. Pérez, L. M.; López, S. A.; Fajes, J. L. H. \& Martín, L. C. Hepatocellular carcinoma. Med., 2020, 13(12), 653-665.

2. Anh, P. T. H. \& Duc, N. B. The situation with cancer control in Vietnam. Jpn. J. Clin. Oncol., 2002, 32, S92-97.

3. Lau, W. Y. Current role of selective internal radiation with yttrium-90 in liver tumors. Future Oncology., 2016, 12(9),1193-204.

4. Wang, E. A.; Stein, J. P.; Bellavia, R. J. \& Broadwell, S. R. Treatment options for unresectable HCC with a focus on SIRT with Yttrium-90 resin microspheres. International Journal of Clinical Practice., 2017, 71(11), 1-15.

5. Dash, A.; Knapp, F. F. \& Pillai, M. Targeted Radionuclide Therapy-An Overview. Curr. Radiopharm., 2014, 6(3), 152-80.

6. Saha, G. B. Fundamentals of Nuclear Pharmacy., 2010.

7. Westcott, M. A.; Coldwell, D. M.; Liu, D. M. \& Zikria, J. F.The development, commercialization, and clinical context of yttrium-90 radiolabeled resin and glass microspheres. Adv. Radiat. Oncol., 2016, 1, 351-364.

8. Murthy, R.; Kamat, P.; Nunez, R. \& Salem, R. Radioembolization of yttrium-90 microspheres for hepatic malignancy. Semin. Intervent. Radiol., 2008, 6(5), 469-478.

9. Gray, B. Polymer based radionuclide containing particulate material., 2003, US20 $100215571 \mathrm{~A} 1$.

10. Bortot, M. B.; Prastalo, S. \& Prado, M. Production and Characterization of Glass Microspheres for Hepatic Cancer Treatment. Procedia Mater. Sci., 2012, 1, 351-358.

11. Aramaki, Y.; Yokoyama, T.; Okaue, Y. \& Watanabe, K. Chemical adsorption of silicic acid to aluminum combined with cation exchange and chelate resins as model compounds of the surface of microbes. Chem.
Geol., 2004, 212(3-4), 339-349.

12. Subramanian, S. Preliminary evaluation of indigenous 90Y-labelled microspheres for therapy of hepatocellular carcinoma. Indian J. Med. Res. Suppl., 2016, 143(1), S74-S81.

13. Łada, W.; Iller, E.; Wawszczak, D.; Konior, M. \& Dziel, T. 90Y microspheres prepared by sol-gel method, promising medical material for radioembolization of liver malignancies. Mater. Sci. Eng. C., 2016, 67, 629-635.

14. Havrdova, M. Field emission scanning electron microscopy (FE-SEM) as an approach for nanoparticle detection inside cells. Micron., 2014, 67, 149-154.

15. Abd Mutalib, M.; Rahman, M. A.; Othman, M. H. D.; Ismail, A. F. \& Jaafar, J. Scanning Electron Microscopy (SEM) and Energy-Dispersive X-Ray (EDX) Spectroscopy. Membrane Characterization., 2017, 161-179.

16. Goldsten, J. O. The messenger gamma-ray and neutron spectrometer. Space Sci. Rev., 2007, 131, 339-391.

17. Paper and thin-layer chromatography. J. Chromatogr. Libr., 1976.

18. Word he. Test for Sterility. World Heal. Organ., 2012.

19. World Health Organization. Test for sterility (Final text for revision of The International Pharmacopoeia). World Heal. Organ., 2012.

20. Nageswaran, G.; Choudhary, Y. S. \& Jagannathan, S. Inductively Coupled Plasma Mass Spectrometry. Spectroscopic Methods for Nanomaterials Characterization., 2017.

21. Niazi, S. Stability Testing of New Drug Substances and Products. Handbook of Pharmaceutical Manufacturing Formulations., 2009.

22. British Pharmacopoeia commission. British Pharmacopoeia 2016. Append. XIII Part. Contam. Sub-visible Part., 2016. 